\title{
Estimating Sovereign Default Risk
}

\author{
Huixin $\mathrm{Bi}^{*}$ and Nora Traum ${ }^{\dagger}$ \\ PRELIMINARY, COMMENTS WELCOME
}

December 31, 2011

\begin{abstract}
This paper uses Bayesian methods to estimate the probability of sovereign default implied by a rational expectations framework and data for two OECD countries: Greece and Italy. We build a real business cycle model that allows interactions among fiscal policy instruments, stochastic 'fiscal limits,' and sovereign default risks. The fiscal policy specification takes into account government spending, lump-sum transfers, and distortionary taxation. A fiscal limit measures the debt level beyond which the government is no longer willing to finance, causing a (partial) default to occur. Using the particle filter to perform likelihood-based inference, we estimate the full nonlinear model for the two countries with post-EMU data. We find substantial differences in the probability of default across the two countries. Although we find that Greece historically had a lower probability of default for a given level of debt, our estimates suggest that the Italian government is more willing to service its debt than the Greek government.
\end{abstract}

JEL Classification: C11; C15; E62; H30; H60

Keywords: Sovereign default risk, sequential Monte Carlo, Bayesian estimation

*Bank of Canada, hbi@bank-banque-canada.ca

†North Carolina State University, nora_traum@ncsu.edu 


\section{Introduction}

Since 2009, mounting fears over a Eurozone sovereign debt crisis have lengthened risks of sovereign debt restructuring and outright default. The long term interest rate spread in the secondary market between Greek government bonds and German bonds rose from 8.99 percentage points in November 2010 to 16.05 in November 2011, and the same spread between Italian and German bonds widened from 1.65 percentage points to 5.19 during the same period. A key issue is to understand the probability of (partial) default in Greece and other Eurozone countries, which is at the heart of this paper.

While there is a growing literature on sovereign default risk premia for developed countries, a divide between empirical and theoretical studies remains. Using rational expectation models, the theoretical studies show that (1) the government's ability to service its debt, or 'fiscal limit,' depends on the underlying macroeconomic fundamentals and, therefore, is country-specific; (2) economic agents' beliefs about the future states of the economy are crucial for the formation of default probabilities (see Bi (2011), Bi and Leeper (2010), and Juessen et al. (2011) among many others). On the other hand, many empirical studies use panel regressions that cannot account for country heterogeneity (see the literature review below), or use historical fiscal responses to construct 'debt limits' that are backward-looking in nature (see Ostry et al. (2010)).

This paper aims to bridge this gap by using Bayesian methods and likelihood-based inference to estimate a standard real business cycle (RBC) model that allows for sovereign default. We estimate the nonlinear model using post-EMU data for Italy and Greece and evaluate each country's historical probability of sovereign default. The dynamic stochastic general equilibrium (DSGE) approach allows us to estimate structural parameters associated with a model of sovereign default, which provides a coherent framework to explore the forward-looking 'fiscal limits,' to identify the country-specific probabilities of default, and to conduct counterfactual exercises.

We consider a closed economy in which the government finances lump-sum transfers and an exogenous level of purchases by collecting distorting taxes and issuing bonds. The bond contract, nevertheless, is not enforceable and depends on the maximum level of debt that the government is able to service, which we call the 'fiscal limit.' The fiscal limit is stochastic and its distribution follows a logistical function. At each period, an effective fiscal limit is drawn from the distribution. If the level of government debt surpasses the effective limit, then the government reneges on a fraction of its debt. Based on the fiscal limit distribution, households can decide the quantity of government debts that they are willing to purchase and the price at which they are willing to pay. 
The economy may switch between the default and no-default regimes endogenously, depending on the government debt level and the fiscal limit distribution. The model, therefore, cannot be solved using a first-order approximation and using the Kalman filter to calculate the likelihood function; instead, it is solved using the monotone mapping method (or policy function iteration) and estimated using the particle filter. After estimating the structural parameters, we construct a model-implied distribution for the fiscal limit that is defined as the sum of the discounted maximum fiscal surplus in all future periods. This model-implied limit reflects the pure economic limit in raising tax revenue: the maximum fiscal surplus is obtained at the peak of the Laffer curve, beyond which a higher tax rate reduces the tax revenue. The estimated distribution for fiscal limit, however, reflects both the political and the economic limit in raising tax revenue. By comparing the model-implied and the estimated distributions, we derive the 'political factor,' which measures the political willingness/ability to service its debt.

We estimate the model for Italy and Greece during the post-EMU period until 2010Q3. Two findings emerge. First, the estimated distribution for fiscal limits is slightly higher for Greece than for Italy. Since the two countries joined the EMU and until 2010Q3, the market had priced the government bonds in such a way that they perceived the Greek government was able to afford a higher debt burden than he Italian government. Second, the modelimplied political factor, nevertheless, is lower for Greece than for Italy. The market perceived that the Italian government was more willing to service its debt than the Greek government by a probability of $12 \%$, suggesting that even from the pure economic point Greece has more room to raises tax revenue and service its debt.

Our paper can contribute to the large empirical literature that studies the determinants of sovereign default risk premia through reduced-form regressions. Focusing on different time periods, Lonning (2000) and Lemmen and Goodhart (1999) find that sovereign yield differentials are correlated with various macroeconomic variables, including government debt to GDP ratios. Codogno et al. (2003) find that default risk explains a substantial part of changes in yield spreads in Italy and Spain, but not in other EU countries. Alesina et al. (1992) find that sovereign default risks are affected by the debt level at high levels of debt, but not influenced by the debt level at low levels of debt. Bernoth et al. (2006) and Haugh et al. (2009) find that deteriorations in fiscal performance increase the spread in a nonlinear way. Some recent papers adopt the time-varying coefficient approach. Bernoth and Erdogan (2011) find the estimated coefficients of the deficit variable was insignificant before the crisis, but becomes positive and shows an increasing trend since 2009. Abmann and Hogrefe (2009) find the debt to GDP ratio was the single most important variable between 2003 and 2007, while Maltritz (2011) show that the budget balance to GDP is very likely to influence spreads. 


\section{Model}

Following Bi (2011), our model is a closed economy with linear production technology, whereby output depends on the level of productivity $\left(A_{t}\right)$ and the labor supply $\left(n_{t}\right)$. Household consumption $\left(c_{t}\right)$ and government purchases $\left(g_{t}\right)$ satisfy the aggregate resource constraint,

$$
c_{t}+g_{t}=A_{t} n_{t}
$$

Technological productivity $A_{t}$ follows the $A R(1)$ process

$$
A_{t}-A=\rho^{A}\left(A_{t-1}-A\right)+\varepsilon_{t}^{A} \quad \varepsilon_{t}^{A} \sim \mathcal{N}\left(0, \sigma_{A}^{2}\right)
$$

\subsection{Government}

The government finances lump-sum transfers to households $\left(z_{t}\right)$ and exogenous and unproductive purchases by levying a tax $\left(\tau_{t}\right)$ on labor income and issuing one-period bonds $\left(b_{t}\right)$. Let $q_{t}$ be the price of the bond in units of consumption at time $t$. For each unit of the bond, the government promises to pay the household one unit of consumption in the next period. However, the bond contract is not enforceable. At each period, a stochastic fiscal limit $\left(b_{t}^{*}\right)$ is drawn from its distribution, $b_{t}^{*} \sim \mathcal{B}^{*}$. We specify the cumulative density function of the fiscal limit distribution as a logistical function with parameters $\eta_{1}$ and $\eta_{2}$ dictating its shape.

$$
p^{*} \equiv P\left(b_{t-1} \geq b_{t}^{*}\right)=\frac{\exp \left(\eta_{1}+\eta_{2} b_{t-1}\right)}{1+\exp \left(\eta_{1}+\eta_{2} b_{t-1}\right)}
$$

If the debt surpasses the fiscal limit, then it partially defaults. The default scheme can be summarized as

$$
\Delta_{t}= \begin{cases}0 & \text { if } b_{t-1}<b_{t}^{*} \\ \delta & \text { if } b_{t-1} \geq b_{t}^{*}\end{cases}
$$

The government's budget constraint is given by

$$
\tau_{t} A_{t} n_{t}+b_{t} q_{t}=\underbrace{\left(1-\Delta_{t}\right) b_{t-1}}_{b_{t}^{d}}+g_{t}+z_{t} .
$$


The tax rate and government spending evolve according to the rules,

$$
\begin{array}{lll}
\tau_{t}=\underbrace{\left(1-\rho^{\tau}\right) \tau+\rho^{\tau} \tau_{t-1}+\varepsilon_{t}^{\tau}}_{u_{t}^{\tau}}+\gamma^{\tau}\left(b_{t}^{d}-b\right) & \varepsilon_{t}^{\tau} \sim \mathcal{N}\left(0, \sigma_{\tau}^{2}\right) \\
g_{t}=\underbrace{\left(1-\rho^{g}\right) g+\rho^{g} g_{t-1}+\varepsilon_{t}^{g}}_{u_{t}^{g}}+\gamma^{g}\left(b_{t}^{d}-b\right) & \varepsilon_{t}^{g} \sim \mathcal{N}\left(0, \sigma_{g}^{2}\right)
\end{array}
$$

with $A R(1)$ components being denoted as $u_{t}^{\tau}$ and $u_{t}^{g}$. The non-distortionary transfers are modeled as a residual in the government budget constraint, exogenously determined by the $\mathrm{AR}(1)$ process,

$$
z_{t}-z=\rho^{z}\left(z_{t-1}-z\right)+\varepsilon_{t}^{z} \quad \varepsilon_{t}^{z} \sim \mathcal{N}\left(0, \sigma_{z}^{2}\right)
$$

Since transfers are not an observable in our estimation, $z_{t}$ can be thought of as capturing all movements in government debt that are not explained by the model.

\subsection{Household}

With access to the sovereign bond market, a representative household chooses consumption $\left(c_{t}\right)$, labor supply $\left(n_{t}\right)$, and bond purchases $\left(b_{t}\right)$ by solving,

$$
\begin{aligned}
& \max \quad E_{0} \sum_{t=0}^{\infty} \beta^{t}\left(\log \left(c_{t}-h \bar{c}_{t-1}\right)+\phi \log \left(1-n_{t}\right)\right) \\
& \text { s.t. }
\end{aligned}
$$

The household's first-order conditions are,

$$
\begin{aligned}
\phi \frac{c_{t}-h \bar{c}_{t-1}}{1-n_{t}} & =A_{t}\left(1-\tau_{t}\right) \\
q_{t} & =\beta E_{t}\left(\left(1-\Delta_{t+1}\right) \frac{c_{t}-h \bar{c}_{t}}{c_{t+1}-h \bar{c}_{t}}\right)
\end{aligned}
$$

The bond price reflects the household's expectation about the probability and magnitude of sovereign default in the next period. The optimal solution to the household's maximization problem must also satisfy the following transversality condition,

$$
\lim _{j \rightarrow \infty} E_{t} \beta^{j+1} \frac{u_{c}(t+j+1)}{u_{c}(t)}\left(1-\Delta_{t+j+1}\right) b_{t+j}=0 .
$$




\subsection{Model Solution}

Other than the specifications for exogenous state variables, the core equilibrium equations are,

$$
\begin{aligned}
q_{t} & =\frac{b_{t}^{d}+z_{t}+g_{t}-\tau_{t} A_{t} n_{t}}{b_{t}} \\
q_{t} & =\beta\left(c_{t}-h c_{t-1}\right) E_{t} \frac{1-\Delta_{t+1}}{c_{t+1}-h c_{t}}
\end{aligned}
$$

The first equation is derived from the government budget constraint, while the second is from the household's first-order conditions. We use the monotone mapping method (or policy function iteration) to solve the decision rule of the bond price in terms of the state vector. At time $t$, the state vector is $\left(b_{t}^{d}, c_{t-1}, A_{t}, u_{t}^{g}, z_{t}, u_{t}^{\tau}\right)$, and the decision rule of the bond price can be written as $q_{t}=q\left(b_{t}^{d}, c_{t-1}, A_{t}, u_{t}^{g}, z_{t}, u_{t}^{\tau}\right)$.

In terms of computation, the most time-consuming part is the loop iterations of the numerical integration in equation (14).

$$
\begin{aligned}
E_{t} \frac{1-\Delta_{t+1}}{c_{t+1}-h c_{t}} & =\int_{\varepsilon_{t+1}^{A}} \int_{\varepsilon_{t+1}^{g}} \int_{\varepsilon_{t+1}^{\tau}} \int_{b_{t+1}^{*}} \frac{1-\Delta_{t+1}}{c_{t+1}-h c_{t}} \\
& =\left.\left(1-\Phi\left(b_{t} \geq b_{t+1}^{*}\right)\right) \int_{\varepsilon_{t+1}^{A}} \int_{\varepsilon_{t+1}^{g}} \int_{\varepsilon_{t+1}^{\tau}} \frac{1}{c_{t+1}-h c_{t}}\right|_{\text {no default }} \\
& +\left.\Phi\left(b_{t} \geq b_{t+1}^{*}\right) \int_{\varepsilon_{t+1}^{A}} \int_{\varepsilon_{t+1}^{g}} \int_{\varepsilon_{t+1}^{\tau}} \frac{1-\delta}{c_{t+1}-h c_{t}}\right|_{\text {default }}
\end{aligned}
$$

Given the utility function, consumption is given by

$$
c_{t}=\frac{\phi h c_{t-1}+\left(A_{t}-g_{t}\right)\left(1-\tau_{t}\right)}{1+\phi-\tau_{t}} .
$$

Thus, the integration in Equation (15) can be re-written as

$$
\begin{aligned}
\int_{\varepsilon_{t+1}^{A}} \int_{\varepsilon_{t+1}^{g}} \int_{\varepsilon_{t+1}^{\tau}} \frac{1}{c_{t+1}-h c_{t}} & =\int_{\varepsilon_{t+1}^{A}} \int_{\varepsilon_{t+1}^{g}} \int_{\varepsilon_{t+1}^{\tau}} \frac{1+\phi-\tau_{t+1}}{\left(1-\tau_{t+1}\right)\left(A_{t+1}-g_{t+1}-h c_{t}\right)} \\
& =\int_{\varepsilon_{t+1}^{\tau}} \frac{1+\phi-\tau_{t+1}}{1-\tau_{t+1}} \int_{\varepsilon_{t+1}^{A}} \int_{\varepsilon_{t+1}^{g}} \frac{1}{A_{t+1}-g_{t+1}-h c_{t}}
\end{aligned}
$$

The logarithmal utility function helps to reduce the 4-dimension integration into 1- and 2-dimension integrations. Appendix A discusses the solution procedure in details. 


\section{Estimation}

The model is estimated for two countries: Italy (1999:2-2010:3) and Greece (2001:2-2010:3). The start dates represent the quarter following each country's official adoption of the Euro, because the interest rates during the pre-Euro period are susceptible to exchange rate risk from which our model abstracts. Five observables are used for the estimation, including real output, government spending, tax revenue, government debt, and a 10-year real interest rate. Appendix B.1 provides a detailed description of the data.

\subsection{Methodology}

We estimate the model using Bayesian methods. The equilibrium system is written in the nonlinear state-space form:

$$
\begin{aligned}
& x_{t}=f\left(x_{t-1}, \epsilon_{t}, \theta\right) \\
& v_{t}=A x_{t}+\xi_{t},
\end{aligned}
$$

where observables $v_{t}$ are linked with model variables $x_{t}$ via the matrix $A, \theta$ denotes model parameters, and $\xi_{t}$ is a vector of measurement error distributed $N(0, \Sigma)$. We assume $\Sigma$ is a diagonal matrix and calibrate the standard deviation of each measurement error to be $20 \%$ of the standard deviation of the corresponding observable variable. ${ }^{1}$

We use a particle filter to approximate the likelihood function. ${ }^{2}$ For a given sequence of observations up to time $t, v^{t}=\left[v_{1}, \ldots, v_{t}\right]$, the particle filter approximates the density $p\left(x_{t} \mid v^{t}, \theta\right)$ with a swarm of particles $x_{t}^{i}(i=1, \ldots, N)$. See appendix B.2 for more details. ${ }^{3}$

We combine the likelihood $L\left(\theta \mid v^{T}\right)$ with a prior density $p(\theta)$ to obtain the posterior density kernel, which is proportional to the posterior density, $p\left(\theta \mid v^{T}\right) \propto p(\theta) L\left(\theta \mid v^{T}\right)$. We assume that parameters are independent a priori. However, we discard any prior draws that do not deliver a unique rational expectations equilibrium, as we restrict the analysis to the determinacy parameter subspace. ${ }^{4}$ We construct the posterior distribution of the parameters using the random walk Metropolis-Hastings algorithm (see appendix B.3 for more details).

\footnotetext{
${ }^{1}$ Estimating measurement errors provides complications in nonlinear models. See Doh (2011) for more discussion on the role of measurement error in nonlinear DSGE model estimation.

${ }^{2}$ The particle filter is applicable for nonlinear and non-Gaussian distributions, to which class our nonlinear model belongs. In addition, the particle filter is more robust than the unscented Kalman filter to sample initialization date, as the particle filter assumes a distribution for the unobserved initial state.

${ }^{3}$ The particle filter is increasingly used to estimate nonlinear DSGE models. Recent examples include An and Schorfheide (2007), Fernandez-Villaverde and Rubio-Ramirez (2007), Armisano and Tristani (2010), Fernandez-Villaverde et al. (2011), and Doh (2011). See Doucet et al. (2001) for a textbook treatment.

${ }^{4} \mathrm{~A}$ technical appendix of the authors provides more discussion on this point.
} 
In each estimation, we sample 38,000 draws from the posterior distribution and discard the first 15,000 draws. ${ }^{5}$ The sample is thinned by every 25 draws, and the likelihood is computed using 40,000 particles.

\subsection{Prior Distributions}

We impose dogmatic priors over some parameters, which are listed in table 1. The discount rate is 0.99 , so that the deterministic net interest rate is $1 \%{ }^{6}$ We calibrate the household's leisure preference parameter $\phi$ such that a household spends $25 \%$ of its time working at the steady state. We calibrate the deterministic debt to GDP ratio, government spending to GDP ratio, and tax rate to the mean values of our data samples.

The priors for the remaining parameters are listed in table 1 . The prior for habit persistence $h$ is similar to those in the linear DSGE estimation literature, for instance Smets and Wouters (2007). For the remaining parameters, we first estimate using ordinary least squares an $\mathrm{AR}(1)$ process for GDP and processes for government spending, the tax rate, and transfers given by equations (5)-(7). ${ }^{7}$ The results are used as general guidance for the region of the parameter space for the $\rho, \sigma$, and $\gamma$ parameters.

For the responses of government spending and taxes to debt, we form priors for the long run responses in terms of percentage deviations from steady state, that is

$$
\gamma^{g, L} \equiv \frac{\gamma^{g}}{\bar{g} \bar{b}\left(1-\rho^{g}\right)}, \quad \gamma^{t, L} \equiv \frac{\gamma^{\tau}}{\bar{\tau} \bar{b}\left(1-\rho^{\tau}\right)}
$$

These values are more comparable to estimates in the literature. Since determinacy is sensitive to the combination of the $\gamma^{\tau, L}$ and $\gamma^{g, L}$ parameters, we restrict the lower bound of the $\gamma^{\tau, L}\left(\gamma^{g, L}\right)$ prior to a value that ensures determinacy when only $\gamma^{\tau, L}\left(\gamma^{g, L}\right)$ finances debt.

For the standard deviations of shocks, we form priors for the standard deviations relative to relevant steady state variables: $\sigma_{k, p} \equiv \sigma_{k} / \bar{J}$ for $J=\{A, g, \tau, z\}$ and $k=\{a, g, \tau, z\}$. This gives standard deviations as percentage deviations, which provides more intuitive comparisons across values.

\footnotetext{
${ }^{5}$ We use Fortran 90 code compiled in Intel Visual Fortran for the estimation. We use the computer server system at the Bank of Canada, which uses Xeon CPU X7460 at 2.66GHz and has 23 processors with $64 \mathrm{G}$ RAM. One evaluation using the particle filter takes 35 seconds. These computational constraints limit the number of draws from the Metropolis-Hastings algorithm.

${ }^{6}$ The mean of our data is $0.6 \%$ for Italy and $0.8 \%$ for Greece.

${ }^{7}$ We back out the model-implied tax rate and transfers series implied by our observables.
} 


\subsubsection{Fiscal Limit}

We estimate one parameter from the fiscal limit distribution, which is represented by equation (3). Given two points on the distribution, $\left(\tilde{b^{*}}, \tilde{p}^{*}\right)$ and $\left(\hat{b^{*}}, \hat{p^{*}}\right)$, the parameters $\eta_{1}$ and $\eta_{2}$ can be uniquely determined by

$$
\eta_{2}=\frac{1}{\tilde{b^{*}}-\hat{b^{*}}} \log \left(\frac{\tilde{p^{*}}}{\hat{p^{*}}} \frac{1-\hat{p^{*}}}{1-\tilde{p^{*}}}\right), \quad \eta_{1}=\log \frac{\tilde{p^{*}}}{1-\tilde{p^{*}}}-\eta_{2} \tilde{b^{*}} .
$$

Since $\left(\tilde{b^{*}}, \tilde{p^{*}}\right)$ and $\left(\hat{b^{*}}, \hat{p^{*}}\right)$ provide a more intuitive description about the fiscal limit distribution than $\eta_{1}$ and $\eta_{2}$, we can fix $\tilde{p}^{*}$ and $\hat{p}^{*}$ at certain levels and estimate the corresponding $\tilde{b^{*}}$ and $\hat{b^{*}}$, instead of estimating $\eta_{1}$ and $\eta_{2}$ directly. We choose $\tilde{p^{*}}=0.3$ and $\hat{p^{*}}=0.999$. Unfortunately, given that defaults are never observed in our data, the data is uninformative about the upper bound of the distribution. Therefore, we estimate $\tilde{b}^{*}$ and fix the difference between $\tilde{b}^{*}$ and $\hat{b}^{*}$ to be $40 \%$ of steady-state output. This difference is chosen to capture the observation that once risk premia begin to rise, they do so rapidly. ${ }^{8}$ Given the lack of guidance for the parameter $\tilde{b}^{*}$, we adopt a diffuse uniform prior over the interval 1.4 to 1.8 .

\subsection{2 $\delta$ Identification}

To our knowledge, this paper is the first attempt to estimate a DSGE model of sovereign default. Thus, prior to estimating the model with real data, we performed several estimations with simulated data. ${ }^{9}$ Unfortunately, the results revealed that we cannot jointly identify the rate of partial default $\delta$ and the fiscal limit parameter $\tilde{b}^{*}$ when the data excludes observed defaults. Parameters related to default affect observable variables through their influence on the risk premium. Since various combinations of $\delta$ and $\tilde{b}^{*}$ are consistent with the same risk premium, we cannot jointly identify the parameters. Given this limitation, we estimate our model for three different calibrations of $\delta: 0.0978,0.05$, and 0.0245 . These calibrations imply annualized rates of default $\delta^{A}$ of $37.88 \%, 20 \%$, and $9.78 \%$ respectively. The range covers the actual default rates of emerging market economies over the period 1983 to 2005, as documented by Bi (2011).

\footnotetext{
${ }^{8}$ The difference of $40 \%$ of output, albeit ad-hoc, should not change the key estimation results as the data is not informative about the upper bound of distribution.

${ }^{9}$ The results are available in a technical appendix from the authors.
} 


\section{Estimation Results}

\subsection{Posterior Estimates}

Tables 2 and 3 compare the medians and $90 \%$ credible intervals of the posterior distributions estimated from the three specifications for each country. For comparison, we also list the estimates implied by a log-linearized version of our model without default. ${ }^{10}$ The data are informative for all of the parameters, as the $90 \%$ credible intervals are smaller than those from the prior distributions.

For the Italian estimates (table 2), several observations are noticeable when comparing across the $\delta$ calibrations. The estimates of $\tilde{b}^{*}$ suggest that there is a $30 \%$ probability of default when agents expect a $37.88 \%$ annualized rate of default and the current debt to annualized steady state GDP ratio is between 1.46-1.60. In contrast, when agents expect a $20 \%$ rate of default, the debt to GDP ratio associated with a $30 \%$ probability of default ranges from 1.44-1.61. The lower $\tilde{b}^{*}$ estimates for a lower $\delta^{A}$ calibration are consistent with theory. The model tries to match the risk premium in the data through the values of $\delta^{A}$ and $\tilde{b}^{*}$. When $\delta^{A}$ is higher, agents expect to lose more of the face-value of debt following a default. Thus, households demand a higher interest rate to compensate for this risk. Thus, for the given risk premium implied by the data, a higher $\tilde{b}^{*}$ is needed to offset a higher $\delta^{A}$ value.

With a low rate of default $\left(\delta^{A}=0.0947\right), \tilde{b}^{*}$ is not identified from Italian data, as the $90 \%$ posterior credible interval mirrors the prior. As can be seen from figure 1, Italian government debt and the 10-year interest rate often negatively co-move over our sample period, ${ }^{11}$ suggesting any risk premium for Italian debt is low over our sample and not easily identifiable. Thus, it appears that with a low default probability, which causes the model to more closely resemble the no default log-linear approximation, the resulting loss in nonlinearity in the model makes the data uninformative about $\tilde{b}^{*}$.

Turning to the Greek estimates (table 3 ), we see that the data is informative about $\tilde{b}^{*}$ for all $\delta^{A}$ calibrations. The estimates of $\tilde{b}^{*}$ suggest that there is a $30 \%$ probability of default when agents expect a $37.88 \%$ annualized rate of default and the current debt to annualized steady state GDP ratio is between 1.58-1.78. In contrast, when agents expect a $9.47 \%$ rate of default, the debt to GDP ratio associated with a $30 \%$ probability of default ranges from 1.40 1.57. As mentioned above, the lower $\tilde{b}^{*}$ estimates for a lower $\delta^{A}$ calibration are consistent

\footnotetext{
${ }^{10}$ These estimates use the Kalman filter to calculate the likelihood function and initialize the MetropolisHastings algorithm using the posterior mode and inverse Hessian at the posterior mode. The system of equations for the log-linearized model are listed in appendix $\mathrm{C}$.

${ }^{11}$ The correlation between the two observables is 0.01 .
} 
with theory.

Interestingly, the $\tilde{b}^{*}$ estimates for Greece are virtually identical for the high and mid range default rate calibrations. Holding $\tilde{b}^{*}$ constant, a higher default rate implies a larger risk premium in the model. In order to avoid this, $\gamma^{g, L}$, the response of government spending to debt, adjusts. In the high $\delta^{A}$ calibration, the posterior for $\gamma^{g, L}$ has more values concentrated at higher levels than the posterior for the mid $\delta^{A}$ calibration. Ceteris paribus, a larger $\gamma^{g, L}$ implies a stronger response of government spending to debt, which lowers the risk premium. Thus, the two specifications imply similar risk premiums despite the fact that $\tilde{b}^{*}$ is the same in each case.

Looking across countries, we find that the debt level associated with a $30 \%$ probability of default is higher in Greece than Italy. This is mainly driven by the stronger responses in Greece of the tax rate and government spending to debt. Over the sample period, Greece appears to have more systematically adjusted taxes and expenditures with fluctuations in its debt. The results are consistent with attitudes towards Greece and Italy during the first half of our sample. For instance, in 2003 Standard and Poor's raised its long-term sovereign credit rating for Greece, noting Greece had consistently narrowed its deficit for the last consecutive seven years. In contrast, Italy was downgraded by Standard and Poor's in 2003, who cited "The weak fiscal position of the general government, which so far has achieved little in terms of structural budget improvements," as one of the major reasons for the downgrade.

\subsection{Model Fit}

To examine how well the model fits the data, we compute smoothed estimates of model variables using the sequential monte carlo approximation of the forward-backward smoothing recursion. Figures 1 and 2 compare the smoothed values from the various model specifications to the observable variables. For each specification, the fitted values are computed using the corresponding posterior mode. For both Italy and Greece, the fit for most variables is accurate, with output being the least precise.

We also compute smoothed estimates of the measurement errors $E\left(\xi_{t} \mid v^{T}, \theta\right)$ and report their mean absolute values and relative standard deviations in table 4 . The standard deviation of each measurement error was fixed to be $20 \%$ of the standard deviation of the respective observable variable. However, for most observables, the estimated relative standard deviation is less than $20 \%$, which suggests that the measurement error did not introduce many constraints for the model fit. The exception is the measurement error for output, which is probably due to the reduced-form nature of the private sector in our model. Relative standard deviations for the nonlinear specifications are smaller than those from a linear model. 
Table 4 also shows that mean absolute values of measurement error are close to zero.

\subsection{Laffer Curve and Fiscal Limit}

In this section, we use the structural estimates to further explore how the market perceives the political willingness/ability to service its debt in Italy and Greece.

The proportional tax on labor income distorts a household's behavior as it lowers the after-tax wage and may induce households to work less. An increase in the tax rate can raise tax revenue when the existing tax rate is low, but it can reduce tax revenue when the existing tax rate is high, producing a Laffer curve. Laffer curves are usually dynamic in the sense that the shape of the Laffer curve depends on the state of the economy. ${ }^{12}$ In our model, for given levels of productivity and government purchases $\left(A_{t}, g_{t}\right)$, the government can collect the maximum level of tax revenue, denoted as $T^{\max }\left(A_{t}, g_{t}\right)$, at the peak of the dynamic Laffer curve, denoted as $\tau^{\max }\left(A_{t}, g_{t}\right)$. The maximum level of debt that the government can possibly pay back is the sum of the discounted maximum fiscal surplus in all future periods.

$$
\mathcal{B}^{\max }=E \sum_{t=0}^{\infty} \beta^{t+1} \frac{u_{c}^{\max }\left(A_{t+1}, g_{t+1}\right)}{u_{c}^{\max }\left(A_{0}, g_{0}\right)}\left(T^{\max }\left(A_{t}, g_{t}\right)-g_{t}-z_{t}\right)
$$

$u_{c}^{\max }$ represents the marginal utility of consumption when the tax rate is at the peak of the Laffer curve $\left(\tau^{\max }\right)$. $\mathcal{B}^{\max }$ is obtained, however, under the assumption that the government is willing to raise the tax at the peak of the Laffer curve, while angry protesters on Athen's streets illustrate the powerful political obstacles to achieve higher tax rates in reality. A reduced-form representation of the political economy perspective is to discount the fiscal surplus not only by a pure rate of time preference $(\beta)$, but also by an additional political factor $\left(\beta^{p o l}\right)$.

$$
\mathcal{B}^{*}=E \sum_{t=0}^{\infty} \beta^{t+1} \beta^{\text {pol }} \frac{u_{c}^{\max }\left(A_{t+1}, g_{t+1}\right)}{u_{c}^{\max }\left(A_{0}, g_{0}\right)}\left(T^{\max }\left(A_{t}, g_{t}\right)-g_{t}-z_{t}\right)
$$

Given a particular set of parameter draws $\left(\theta_{i}\right)$, we can compute the model-implied distribution, $\mathcal{B}^{\max }\left(\theta_{i}\right)$, and the corresponding $\tilde{b}^{\max }\left(\theta_{i}\right)$, at which the default probability is 0.3 . $\tilde{b}_{i}^{*}$ is the corresponding draw for the debt threshold from our estimated fiscal distribution. Thus, the ratio between the estimated $\tilde{b}_{i}^{*}$ and the model-implied $\tilde{b}_{i}^{\text {max }}$ gives the political factor $\beta_{i}^{\text {pol }}$.

To compute the model-implied distribution, given the logarithm utility function, the tax

\footnotetext{
${ }^{12}$ Trabandt and Uhlig (2011) compute Laffer curves for the United States and 15 European countries using a neoclassical model.
} 
revenue $\left(T_{t}\right)$ can be written as,

$$
\begin{aligned}
T_{t} & =\tau_{t} \frac{A_{t}\left(1-\tau_{t}\right)+\phi g_{t}+\phi h c_{t-1}}{1+\phi-\tau_{t}} \\
& =(1+2 \phi) A_{t}-\phi\left(g_{t}+h c_{t-1}\right)-\left(A_{t}\left(1+\phi-\tau_{t}\right)+\frac{(1+\phi) \phi\left(A_{t}-h c_{t-1}-g_{t}\right)}{1+\phi-\tau_{t}}\right)
\end{aligned}
$$

The tax revenue reaches to the maximum level $\left(T_{t}^{\max }\right)$ when the tax rate reaches the peak point of the Laffer curve $\left(\tau_{t}^{\max }\right)$.

$$
\tau_{t}^{\max }=1+\phi-\sqrt{\frac{(1+\phi) \phi\left(A_{t}-g_{t}-h c_{t-1}\right)}{A_{t}}}
$$

There exists a unique mapping between the exogenous state space $\left(A_{t}, g_{t}\right)$ to $\tau_{t}^{\max }$ and $T_{t}^{\max }$. For a given set of parameter draws $\left(\theta_{i}\right)$, the distribution of fiscal limit $\left(\mathcal{B}^{\max }\left(\theta_{i}\right)\right)$ can be obtained using Markov Chain Monte Carlo simulation:

1. First, for each simulation $j$, we randomly draw the shocks for productivity $\left(A_{t}^{j}\right)$, government purchases $\left(g_{t}^{j}\right)$, and the transfers $\left(z_{t}^{j}\right)$ for $T=1500$ periods with the first $T_{0}=500$ as burn-in period. Assuming that the tax rate is always at the peak of the dynamic Laffer curves, we compute the paths of all other variables following the household first-order conditions and the budget constraints, and the discounted sum of maximum fiscal surplus is specified below.

$$
B_{j}^{\max }\left(\theta_{i}\right)=\sum_{t=T_{0}}^{t=T} \beta^{t+1-T_{0}} \frac{u_{c}^{\max }\left(A_{t+1}^{j}, g_{t+1}^{j}\right)}{u_{c}^{\max }\left(A_{T_{0}}^{j}, g_{T_{0}}^{j}\right)}\left(T^{\max }\left(A_{t}^{j}, g_{t}^{j}\right)-g_{t}^{j}-z_{t}^{j}\right)
$$

2. Second, we repeat the simulation for 10000 times and obtain the distribution $\mathcal{B}^{\max }\left(\theta_{i}\right)$ using the simulated $B_{j}^{\max }\left(\theta_{i}\right)(j=1, \ldots, 10000) .{ }^{13}$

3. Finally, using Kernal estimation, we can derive the cumulative density function for the model-implied distribution $\mathcal{B}^{\max }\left(\theta_{i}\right)$ for those particular parameter draws, and therefore obtain the model-implied debt level $\tilde{b}^{\max }\left(\theta_{i}\right)$, at which the default probability is 0.3 .

By repeating the above procedure to the posterior parameter draws $\left(\theta_{i}, i=1 \ldots 920\right)$, we obtain a set of $\tilde{b}^{\max }\left(\theta_{i}\right)$. The top row in table (5) shows the median and the $90 \%$

\footnotetext{
${ }^{13}$ Increasing the number of simulations doesn't change the simulated distribution much.
} 
credible intervals for $\tilde{b}^{\text {max }}$ for Italy and Greece for various $\delta^{A}$ calibrations. The default rate specifications do not have much of an impact in either Italy or Greece. However, the modelimplied debt threshold is higher in Greece than in Italy. This implies that, were both Italian and Greek governments willing to tax at the peak of their Laffer curves, the latter would be able to service a higher level of debt, assuming the average levels of government spending and transfers in the future are the same as the historical levels, which are higher in Italy than in Greece. Bi (2011) shows that a lower level of government spending or transfers raises the fiscal surplus at each period and can significantly raise the fiscal limit.

For comparison, the second row in table (5) lists the median and the $90 \%$ credible confidence intervals for the estimated debt threshold $\tilde{b}^{*}$ in both countries. Interestingly, the implied political factor $\beta^{\text {pol }}$, calculated as the ratio between the estimated $\tilde{b}^{*}$ and the modelimplied $\tilde{b}^{\max }$, is lower in Greece than in Italy. The median is 0.62-0.65 for Italy, but 0.45-0.5 for Greece. One interpretation is that the market perceives the Italian government is willing to raise taxes to the peak of Laffer curve with a probability of $62 \%$ to $65 \%$, while the probability of the Greek government's willingness is a mere $45 \%$ to $50 \%$. In other words, the political willingness to service debt is $12 \%$ higher in Italy than in Greece.

\section{Conclusion}

This paper uses Bayesian methods to estimate the probability of sovereign default for Greece and Italy. We build a real business cycle model that allows the interactions among fiscal policy instruments, the stochastic fiscal limit, and sovereign default risks. The fiscal policy specification takes into account government spending, lump-sum transfers, and distortionary taxation. We model the fiscal limit distribution with a logistical function, which illustrates the market's belief about the government's ability to service its debt at various debt levels.

Using the particle filter to perform likelihood-based inference, we estimate the full nonlinear model for the two countries with post-EMU data. We find substantial differences in the probability of default across the two countries. For a given level of debt, we find that Greece historically had a lower probability of default than Italy. In addition, we find that the level of debt associated with a given level of default depends on agents' expectations about the size of a default.

Having estimated the structural parameters of the model, we compute the dynamic Laffer curves for each country and calculate the pure economic fiscal limit, that is the maximum level of debt that the government is able to service. We compare the difference between the estimated fiscal limit distributions and the pure economic fiscal limit and find that the Italian government appears to be more willing to service its debt than the Greek government. 
Although our nonlinear model allows complex interactions among fiscal policy instruments and the fiscal limit, it is only a first step to understanding and estimating probabilities of default for developed countries. In this paper, we show how to estimate a model with sovereign default. To understand fully the complexities associated with default risk, several other features are worthy of modeling attention, including the interaction of monetary and fiscal policies; the interaction of the financial sector and the government; and open economy issues including foreign holdings of debt and risks of contagion. 


\section{References}

Abmann, C. and Hogrefe, J. (2009). Determinants of government bond spreads in the Euro area in good times as in bad. Kiel Working Papers 1548, Kiel Institute for the World Economy.

Alesina, A., De Broeck, M., Prati, A. and Tabellini, G. (1992). Default risk on government debt in oecd countries. Economic Policy, 7 (15), 428-463.

An, S. and Schorfheide, F. (2007). Bayesian analysis of dsge models. Econometrics Reviews, 26 (2-4), 113-172.

Armisano, G. and Tristani, O. (2010). Euro area inflation persistence in an estimated nonlinear dsge model. Journal of Economic Dynamics and Control, 34 (10), 1837-1858.

Bernoth, K. and Erdogan, B. (2011). Sovereign bond yield spreads: A time-varying coefficient approach. Journal of International Money and Finance, (forthcoming).

—, von Hagen, J. and Schuknecht, L. (2006). Sovereign risk premiums in the european government bond market. GESY Discussion Paper No. 151.

BI, H. (2011). Sovereign default risk premia, fiscal limits and fiscal policy. European Economic Review, (forthcoming).

- and Leeper, E. M. (2010). Sovereign debt risk premia and fiscal policy in sweden. NBER Working Papers 15810.

Codogno, L., Favero, C. and Missale, A. (2003). Yield spreads on emu government bonds. Economic Policy, 18 (37), 503-532.

DoH, T. (2011). Yield curve in an estimated nonlinear macro model. Journal of Economic Dynamics and Control, 35 (8), 1229-1244.

Doucet, A., De Freitas, J. and Gordon, N. (2001). Sequential Monte Carlo Methods in Practice. Springer Series in Statistics for Engineering and Information Science, New York: Springer-Verlag.

Fernandez-Villaverde, J., Guerron-Quintana, P. A., Rubio-Ramirez, J. F. and URIBE, M. (2011). Risk matters: The real effects of stochastic volatility shocks. American Economic Review, 101 (6), 2530-2561. 
— and Rubio-Ramirez, J. (2007). Estimating macroeconomic models: A likelihood approach. Review of Economic Studies, 74 (4), 1059-1087.

Haugh, D., Ollivaud, P. and Turner, D. (2009). What drives sovereign risk premiums? an analysis of recent evidence from the euro area. OECD Economics Department Working Papers, No. 718.

Juessen, F., Linnemann, L. and Schabert, A. (2011). Default risk premia on government bonds in a quantitative macroeconomic model. Manuscript.

Kitagawa, G. (1996). Monte carlo filter and smoother for non-gaussian nonlinear state space models. Journal of Computational and Graphical Statistics, 5, 1-25.

Lemmen, J. J. and Goodhart, C. A. (1999). Credit risks and european government bond markets: A panel data econometric analysis. Eastern Economic Journal, 25, 77-107.

Lonning, I. M. (2000). Default premia on european government debt. Review of World Economics, 136 (2), 259-283.

Maltritz, D. (2011). Determinants of sovereign yield spreads in the eurozone: A bayesian approach. Journal of International Money and Finance, (forthcoming).

Ostry, J. D., Ghosh, A. R., Kim, J. I. and Qureshi, M. S. (2010). Fiscal space. IMF Staff Position Note (SPN/10/11).

Smets, F. and Wouters, R. (2007). Shocks and frictions in u.s. business cycles: A bayesian dsge approach. American Economic Review, 97 (3), 586-606.

Trabandt, M. and Uhlig, H. (2011). The laffer curve revisited. Journal of Monetary Economics, (forthcoming). 


\section{A Solving the Nonlinear Model}

Other than the end-of-period government debt, all other variables are either exogenous or can be computed in terms of the current state $\psi_{t}=\left(b_{t}^{d}, c_{t-1}, A_{t}, u_{t}^{g}, z_{t}, u_{t}^{\tau}\right)$.

$$
\begin{aligned}
& \tau_{t}=u_{t}^{\tau}+\gamma^{\tau}\left(b_{t}^{d}-b\right) \\
& g_{t}=u_{t}^{g}+\gamma^{g}\left(b_{t}^{d}-b\right) \\
& z_{t}=\left(1-\rho^{z}\right) z+\rho^{z} z_{t-1}+\varepsilon_{t}^{z} \\
& A_{t}=\left(1-\rho^{A}\right) A+\rho^{A} A_{t-1}+\varepsilon_{t}^{A} \\
& c_{t}= \frac{\phi h c_{t-1}+\left(A_{t}-g_{t}\right)\left(1-\tau_{t}\right)}{1+\phi-\tau_{t}} \\
& \Delta_{t}= \begin{cases}0 & \text { if } b_{t-1}<b_{t}^{*} \\
\delta & \text { if } b_{t-1} \geq b_{t}^{*}\end{cases}
\end{aligned}
$$

The decision rule for government debt, $b_{t}=f^{b}\left(\psi_{t}\right)$, is solved in the following steps:

- Step 1: Define the grid points by discretize the state space $\psi_{t}$. Make an initial guess of the decision rule $f_{0}^{b}$ over the state space.

- Step 2: At each grid point, solve the following core equation and obtain the updated rule $f_{i}^{b}$ using the given rule $f_{t-1}^{b}$. The integral in the right-hand side is evaluated as described in Section 2.3 using numerical quadrature.

$$
\frac{b_{t}^{d}+z_{t}+g_{t}-\tau_{t} A_{t} n\left(\psi_{t}\right)}{f_{i}^{b}\left(\psi_{t}\right)}=\beta\left(1-\Delta_{t+1}\right) E_{t} \frac{c\left(\psi_{t}\right)-h c_{t-1}}{c\left(\psi_{t+1}\right)-h c\left(\psi_{t}\right)}
$$

where $\psi_{t+1}=(\underbrace{\left(f_{i-1}^{b}\left(\psi_{t}\right), \Delta_{t+1}\right)}_{b_{t}^{d}}, c_{t}, A_{t+1}, u_{t+1}^{g}, z_{t+1}, u_{t+1}^{\tau})$.

- Step 3: Check the convergence of the decision rule. If $\left|f_{i}^{b}-f_{i-1}^{b}\right|$ is above the desired tolerance (set to $1 e-5$ ), go back to step 2; other wise, $f_{i}^{b}$ is the decision rule and used to evaluate the particle filter as described below. 


\section{B Estimation}

\section{B.1 Data Description}

Data are for Italy and Greece. For each series, we transform the series into percentage deviations from the mean value of the sample and detrend each time series with its own linear trend.

Real GDP. Taken from the OECD volume 88 and constructed by dividing the quarterly nominal GDP series by the GDP deflator.

Debt. Using the annual gross debt to GDP ratio series from the OECD volume 88, we interpolate the series to a quarterly frequency using the method of Chow and Lin (1971). ${ }^{14}$ The quarterly level of debt is found by multiplying the debt to GDP ratio by the real GDP series.

Gov. Spending. Using the annual government final expenditure to GDP ratio series from the OECD volume 88 , we interpolate the series to a quarterly frequency using the method of Chow and Lin (1971). The quarterly level of government spending is found by multiplying the government spending to GDP ratio by the real GDP series.

Tax Revenue. Use the annual tax revenue to GDP ratio (tax revenue consisting of indirect and direct taxes and social security contributions) from the OECD volume 88 (TIND $+\mathrm{TY}+\mathrm{SSRG}$ ), we interpolate the series to a quarterly frequency using the method of Chow and Lin (1971). The quarterly level of tax revenue is found by multiplying the tax revenue to GDP ratio by the real GDP series.

Real Interest Rate. To construct a 10-year real interest rate measure, we use data for the nominal interest rate (taken from the BIS) and the expected inflation rate. Our measure of expected inflation for Italy comes from Consensus Economics, who ask a number of professional forecasters based in a variety of countries about their expectations of a wide range of economic variables. We use their long-term (five to ten year) forecast, which has been published biannually in April and October since the autumn of $1989 .{ }^{15}$ For Greece, we use the expected inflation series from the Survey of Professional Forecasts EU-area five year ahead expected inflation series, which is a general euro-wide inflation series. The gross real interest rate is constructed using the relation

$$
R_{t}=\frac{1+i_{t}}{1+\pi_{t}^{e}}
$$

\footnotetext{
${ }^{14}$ We use the quarterly real GDP series as a relative measure for the interpolation. Forni, Monteforte, and Sessa (2009) use a similar approach.

${ }^{15}$ This is the same method used in Upper and Worms (2003), and more details about the construction of real long term interest rates can be found therein.
} 


\section{B.2 Particle Filter Algorithm}

Let $v^{T}$ denote $\left\{\hat{v}_{t}\right\}_{t=1}^{T}$, which evolves according to equations (19) and (20) in the text. To evaluate the likelihood function $L\left(\theta \mid v^{T}\right)$, we use a sequential Monte Carlo filter (specifically, the sequential importance resampling filter of Kitagawa (1996)). The algorithm is as follows:

- Step 1. Initialize the state variable $x_{0}$ by generating 40,000 values from the unconditional distribution $p\left(x_{0} \mid \theta\right)$. Denote these particles by $x_{0}^{i}$ for $i=1, \ldots, 40,000$. Draw 40, 000 values from standard normal distributions for each of the structural shocks $\left(\epsilon^{A}\right.$, $\left.\epsilon^{g}, \epsilon^{t}, \epsilon^{z}\right)$ and 40,000 values from a standard uniform distribution for fiscal limit probabilities. Denote the vector of these particles by $u^{i}$. By induction, in period $t$ these are particles $u^{t \mid t-1, i}$.

- Step 2. Construct $x^{t \mid t-1, i}$ using equation (19) in the text. Assign to each draw $\left(u^{t \mid t-1, i}\right.$, $\left.x^{t \mid t-1, i}\right)$ a weight defined as:

$$
w_{t}^{i}=\frac{1}{(2 \pi)^{5 / 2}|\Sigma|^{1 / 2}} \exp \left[-\frac{1}{2}\left(y_{t}-A x^{t \mid t-1, i}\right)^{\prime} \Sigma\left(y_{t}-A x^{t \mid t-1, i}\right)\right]
$$

- Step 3. Normalize the weights:

$$
\tilde{w}_{t}^{i}=\frac{w_{t}^{i}}{\sum_{i=1}^{N} w_{t}^{i}}
$$

Update the values of $x^{t \mid t-1, i}$ by sampling with replacement 40,000 values of $x^{t \mid t-1, i}$ using the relative weights $\tilde{w}_{t}^{i}$ and the residual resampling algorithm.

- Repeat steps 2-3 for $t \leq T$.

The log-likelihood function is approximated by

$$
L\left(\theta \mid v^{T}\right) \simeq \sum_{t=1}^{T} \ln \left(\frac{1}{40,000} \sum_{i=1}^{40,000} w_{t}^{i}\right)
$$

\section{B.3 MCMC Algorithm}

The random walk Metropolis-Hastings algorithm used for estimation works as follows:

- Step 1. Compute the posterior log-likelihood for 500 draws from the priors. Call the draw with the highest posterior $\log$-likelihood value $\theta^{*}$.

- Step 2. Starting from $\theta^{*}$, generate a MCMC chain using the following random-walk proposal density

$$
\theta_{j+1}^{\text {prop }}=\theta_{j}^{\text {prop }}+c \mathcal{N}(0, \Lambda), \quad j=1, \ldots, 100,000
$$


where $\Lambda$ is the covariance matrix of 500 draws from the priors and $c>0$ is a tuning parameter set to determine the acceptance ratio.

- Step 3. Compute the acceptance ratio $\varphi=\min \left\{\frac{p\left(\theta_{j+1}^{\text {prop }} \mid v^{T}\right)}{p\left(\theta_{j} \mid v^{T}\right)}, 1\right\}$. Given a draw $u$ from the standard uniform distribution. Then $\theta_{j+1}=\theta_{j+1}^{\text {prop }}$ if $u<\varphi$ and $\theta_{j+1}=\theta_{j}$ otherwise. Repeat for $j=1, \ldots, 10,000$.

- Step 4. Update the random walk proposal density in the following way. Update $\Lambda$ to be the covariance matrix from the previous draws $\left\{\theta_{j}\right\}_{1}^{10,000}$. Update $\theta^{*}$ to be the mean of previous draws $\left\{\theta_{j}\right\}_{1}^{10,000}$. Starting from the new $\theta^{*}$, proceed through steps 2 and 3 for 38,000 draws from the new MCMC chain.

We burn the first 15,000 draws from the final MCMC chain and thin every 25 draws.

\section{Log-Linearized Model Equations}

The log-linearized system of equations for the variant of the model without default are:

$$
\begin{gathered}
\hat{c}_{t}-\frac{1}{1+h} E_{t} \hat{c}_{t+1}+\frac{1-h}{1+h} \hat{R}_{t}=\frac{h}{1+h} \hat{c}_{t-1} \\
\frac{1}{1-h} \hat{c}_{t}+\frac{n}{1-n} \hat{n}_{t}-\hat{A}_{t}+\frac{\tau}{1-\tau} \hat{\tau}_{t}=\frac{h}{1-h} \hat{c}_{t-1} \\
\frac{c}{y} \hat{c}_{t}+\frac{g}{y} \hat{g}_{t}=\hat{A}_{t}+\hat{n}_{t} \\
\frac{b}{y} \hat{b}_{t}-\frac{g}{y} \hat{g}_{t}-\frac{z}{y} \hat{z}_{t}+\tau\left(\hat{\tau}_{t}+\hat{A}_{t}+\hat{n}_{t}\right)=R * \frac{b}{y}\left(\hat{R}_{t-1}+\hat{b}_{t-1}\right) \\
\hat{g}_{t}=\left(1-\rho^{g}\right) \hat{g}_{t-1}-\gamma^{g, L}\left(1-\rho^{g}\right) b_{t-1}+\sigma_{g, p} \epsilon_{t}^{g}, \quad \epsilon_{t}^{g} \sim N(0,1) \\
\hat{\tau}_{t}=\left(1-\rho^{\tau}\right) \hat{\tau}_{t-1}+\gamma^{\tau, L}\left(1-\rho^{\tau}\right) b_{t-1}+\sigma_{\tau, p} \epsilon_{t}^{\tau}, \quad \epsilon_{t}^{\tau} \sim N(0,1) \\
\hat{z}_{t}=\left(1-\rho^{z}\right) \hat{z}_{t-1}+\sigma_{z, p} \epsilon_{t}^{z}, \quad \epsilon_{t}^{z} \sim N(0,1) \\
\hat{A}_{t}=\left(1-\rho^{a}\right) \hat{A}_{t-1}+\sigma_{a, p} \epsilon_{t}^{a}, \quad \epsilon_{t}^{z} \sim N(0,1)
\end{gathered}
$$



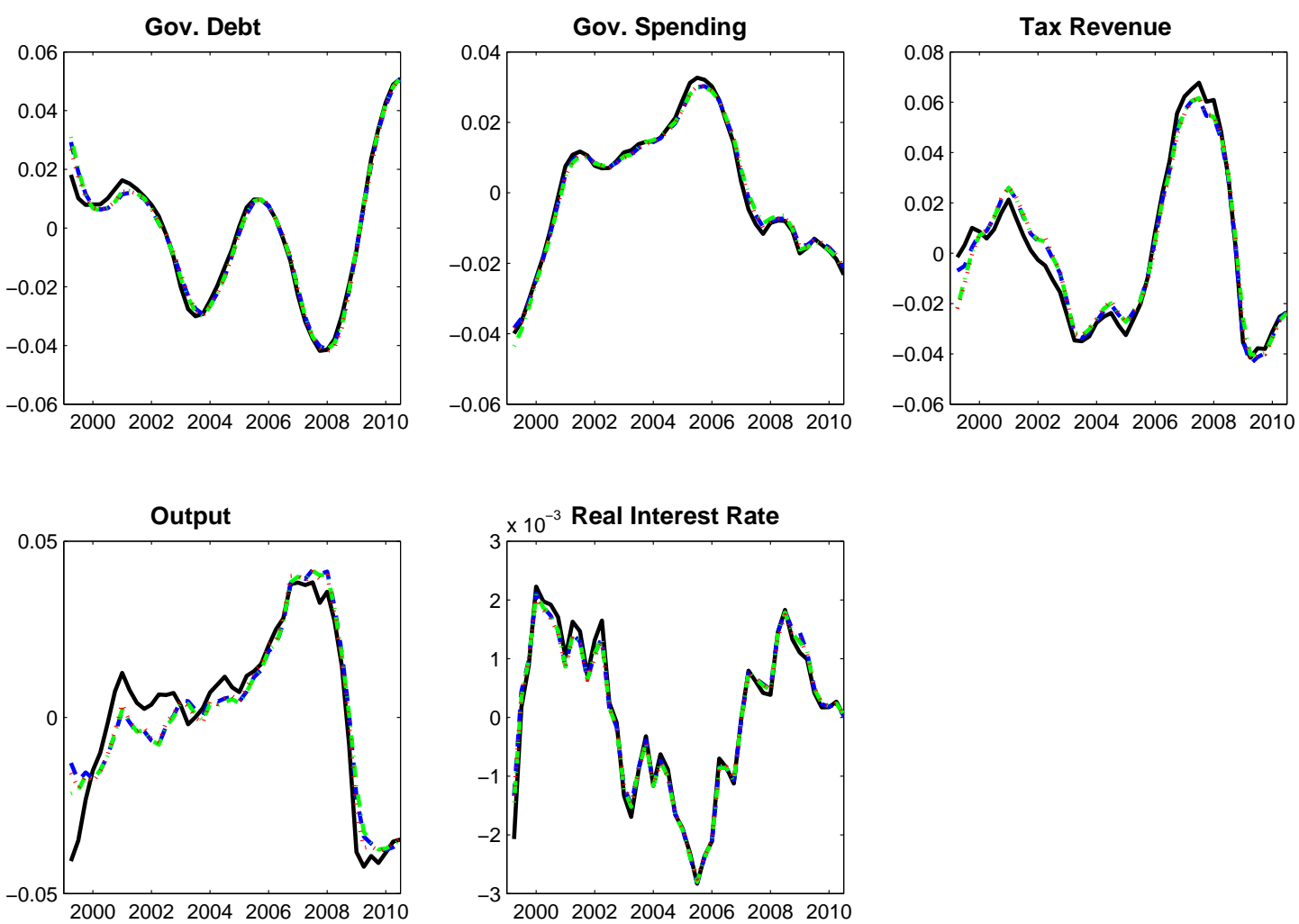

Figure 1: Fitted values for various estimations. Black, solid lines: data. Blue, dashed lines: Nonlinear model with $\delta^{A}=0.3788$. Red, dotted-dashed lines: Nonlinear model with $\delta^{A}=$ 0.0947. Green, dotted lines: Linear model. 

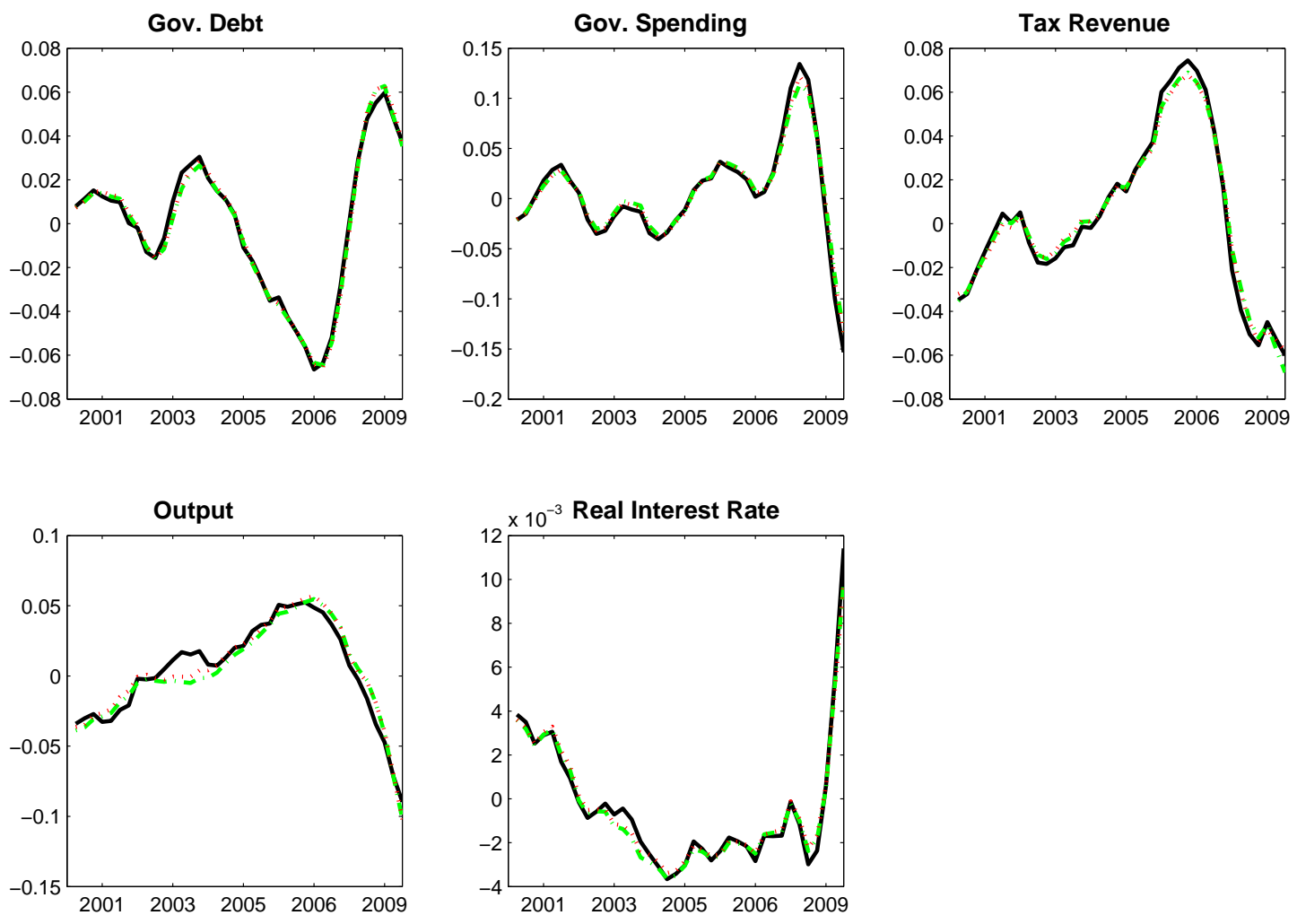

Figure 2: Fitted values for various estimations. Black, solid lines: data. Blue, dashed lines: Nonlinear model with $\delta^{A}=0.3788$. Red, dotted-dashed lines: Nonlinear model with $\delta^{A}=$ 0.0947. Green, dotted lines: Linear model. 
Table 1: Calibration and priors. For priors, the distribution and mean are denoted, as well as the standard deviation in parenthesis.

\begin{tabular}{lcc} 
Calibration & & \\
& Italy & Greece \\
\hline$\beta$ & 0.99 & 0.99 \\
$\bar{n}$ & 0.75 & 0.75 \\
$\bar{g} / \bar{y}$ & 0.1966 & 0.1795 \\
$\bar{b} / \bar{y}$ & $1.19^{*} 4$ & $1.14^{*} 4$ \\
$\tau$ & 0.4148 & 0.3387 \\
\hline
\end{tabular}

\begin{tabular}{|c|c|c|c|}
\hline Prio & s & Italy & Greece \\
\hline$h$ & Beta & $\begin{array}{c}0.5 \\
(0.2)\end{array}$ & $\begin{array}{c}0.5 \\
(0.2)\end{array}$ \\
\hline$\tilde{b}^{*}$ & Uniform & $\begin{array}{c}1.6 \\
(0.013)\end{array}$ & $\begin{array}{c}1.6 \\
(0.013)\end{array}$ \\
\hline$\gamma^{\tau, L}$ & Gamma & $\begin{array}{c}1.1 \\
(0.3)\end{array}$ & $\begin{array}{c}1.1 \\
(0.3)\end{array}$ \\
\hline$\gamma^{g, L}$ & Gamma & $\begin{array}{c}0.4 \\
(0.2)\end{array}$ & $\begin{array}{l}1.1 \\
(0.3)\end{array}$ \\
\hline$\rho^{a}$ & Beta & $\begin{array}{c}0.8 \\
(0.1)\end{array}$ & $\begin{array}{c}0.8 \\
(0.1)\end{array}$ \\
\hline$\rho^{g}$ & Beta & $\begin{array}{c}0.8 \\
(0.1)\end{array}$ & $\begin{array}{c}0.8 \\
(0.1)\end{array}$ \\
\hline$\rho^{\tau}$ & Beta & $\begin{array}{c}0.8 \\
(0.1)\end{array}$ & $\begin{array}{c}0.8 \\
(0.1)\end{array}$ \\
\hline$\rho^{z}$ & Beta & $\begin{array}{c}0.3 \\
(0.1)\end{array}$ & $\begin{array}{c}0.8 \\
(0.1)\end{array}$ \\
\hline$\sigma_{a, p}$ & Gamma & $\begin{array}{c}0.005 \\
(0.003)\end{array}$ & $\begin{array}{c}0.005 \\
(0.003)\end{array}$ \\
\hline$\sigma_{g, p}$ & Gamma & $\begin{array}{c}0.005 \\
(0.003)\end{array}$ & $\begin{array}{c}0.005 \\
(0.003)\end{array}$ \\
\hline$\sigma_{\tau, p}$ & Gamma & $\begin{array}{c}0.005 \\
(0.003)\end{array}$ & $\begin{array}{c}0.005 \\
(0.003)\end{array}$ \\
\hline$\sigma_{z, p}$ & Gamma & $\begin{array}{c}0.2 \\
(0.1)\end{array}$ & $\begin{array}{c}0.2 \\
(0.1)\end{array}$ \\
\hline
\end{tabular}


Table 2: Italy Estimates.

\begin{tabular}{|c|c|c|c|c|c|c|c|c|c|c|}
\hline & \multicolumn{2}{|r|}{ Prior } & \multicolumn{2}{|c|}{ Posterior: $\delta^{A}=\mathbf{0 . 3 7 8 8}$} & \multicolumn{2}{|c|}{ Posterior: $\delta^{A}=\mathbf{0 . 2}$} & \multicolumn{2}{|c|}{ Posterior: $\delta^{A}=\mathbf{0 . 0 9 4 7}$} & \multicolumn{2}{|c|}{ Posterior: Linear } \\
\hline $\bar{~} \underset{\sim}{h}$ & 0.5 & $\overline{[0.17,0.83]}$ & $\overline{0.14}$ & $\overline{[0.06,0.21]}$ & $\overline{0.11}$ & $\overline{[0.03,0.24]}$ & 0.11 & $\overline{[0.02,0.26]}$ & 0.05 & $\overline{[0.01,0.11]}$ \\
\hline$\tilde{b}^{*}$ & 1.6 & {$[1.42,1.78]$} & 1.52 & {$[1.46,1.60]$} & 1.47 & {$[1.44,1.51]$} & 1.60 & {$[1.44,1.78]$} & - & - \\
\hline$\gamma^{\tau, L}$ & 1.1 & {$[0.64,1.67]$} & 0.53 & {$[0.45,0.66]$} & 0.56 & {$[0.45,0.68]$} & 0.56 & {$[0.28,0.70]$} & 0.45 & {$[0.33,0.56]$} \\
\hline$\gamma^{g, L}$ & 0.4 & {$[0.12,0.82]$} & 0.30 & {$[0.16,0.56]$} & 0.59 & {$[0.17,0.82]$} & 0.54 & {$[0.25,0.80]$} & 0.28 & {$[0.09,0.60]$} \\
\hline$\rho^{a}$ & 0.8 & {$[0.61,0.94]$} & 0.96 & {$[0.95,0.97]$} & 0.96 & {$[0.95,0.97]$} & 0.96 & {$[0.94,0.98]$} & 0.96 & {$[0.95,0.97]$} \\
\hline$\rho^{g}$ & 0.8 & {$[0.61,0.94]$} & 0.84 & {$[0.72,0.87]$} & 0.86 & {$[0.80,0.90]$} & 0.86 & {$[0.77,0.91]$} & 0.87 & {$[0.80,0.94]$} \\
\hline$\rho^{z}$ & 0.3 & {$[0.15,0.48]$} & 0.49 & {$[0.38,0.67]$} & 0.46 & {$[0.35,0.63]$} & 0.50 & {$[0.32,0.66]$} & 0.46 & {$[0.29,0.63]$} \\
\hline$\rho^{\tau}$ & 0.8 & {$[0.61,0.94]$} & 0.84 & {$[0.81,0.85]$} & 0.84 & {$[0.82,0.87]$} & 0.84 & {$[0.81,0.88]$} & 0.85 & {$[0.83,0.87]$} \\
\hline$\sigma_{a, p}$ & 0.005 & {$[0.001,0.01]$} & 0.010 & {$[0.009,0.012]$} & 0.01 & {$[0.009,0.011]$} & 0.01 & {$[0.009,0.012]$} & 0.01 & {$[0.008,0.012$} \\
\hline$\sigma_{g, p}$ & 0.005 & {$[0.001,0.01]$} & 0.006 & {$[0.005,0.007]$} & 0.006 & {$[0.005,0.007]$} & 0.006 & {$[0.005,0.008]$} & 0.005 & {$[0.004,0.007$} \\
\hline$\sigma_{z, p}$ & 0.2 & {$[0.07,0.39]$} & 0.13 & {$[0.10,0.17]$} & 0.14 & {$[0.11,0.19]$} & 0.13 & {$[0.10,0.18]$} & 0.13 & {$[0.10,0.18]$} \\
\hline$\sigma_{\tau, p}$ & 0.005 & {$[0.001,0.01]$} & 0.007 & {$[0.006,0.008]$} & 0.008 & {$[0.006,0.008]$} & 0.008 & {$[0.006,0.009]$} & 0.007 & {$[0.006,0.009$} \\
\hline
\end{tabular}

Table 3: Greece Estimates.

\begin{tabular}{|c|c|c|c|c|c|c|c|c|c|c|}
\hline & \multicolumn{2}{|c|}{ Prior } & \multicolumn{2}{|c|}{$\begin{array}{lc}\text { Posterior: } & \delta^{A}=\mathbf{0 . 3 7 8 8} \\
\text { median } & {[5,95]} \\
\end{array}$} & \multicolumn{2}{|c|}{$\begin{array}{ll}\text { Posterior: } & \delta^{A}=\mathbf{0 . 2} \\
\text { median } & {[5,95]} \\
\end{array}$} & \multicolumn{2}{|c|}{$\begin{array}{lc}\text { Posterior: } & \delta^{A}=\mathbf{0 . 0 9 4 7} \\
\text { median } & {[5,95]}\end{array}$} & \multicolumn{2}{|c|}{$\begin{array}{ll}\text { Posterior: Linear } \\
\text { median } & {[5,95]} \\
\end{array}$} \\
\hline 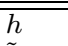 & $\overline{0.5}$ & $\overline{[0.17,0.83]}$ & 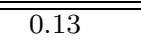 & 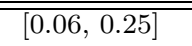 & 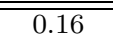 & 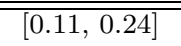 & 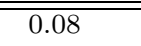 & 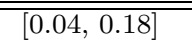 & 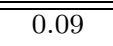 & 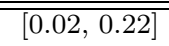 \\
\hline$\tilde{b}^{*}$ & 1.6 & {$[1.42,1.78]$} & 1.67 & {$[1.58,1.78]$} & 1.69 & {$[1.57,1.79]$} & 1.45 & {$[1.40,1.57]$} & - & - \\
\hline$\gamma^{\tau, L}$ & 1.1 & {$[0.64,1.67]$} & 0.82 & {$[0.54,1.09]$} & 0.76 & {$[0.46,1.00]$} & 1.14 & {$[0.94,1.48]$} & 0.62 & {$[0.41,0.98]$} \\
\hline$\gamma^{g, L}$ & 1.1 & {$[0.64,1.67]$} & 1.73 & {$[0.87,2.97]$} & 1.53 & {$[1.22,1.85]$} & 1.51 & {$[1.08,1.78]$} & 1.42 & {$[0.85,2.17]$} \\
\hline$\rho^{a}$ & 0.8 & {$[0.61,0.94]$} & 0.91 & {$[0.89,0.92]$} & 0.91 & {$[0.89,0.93]$} & 0.90 & {$[0.88,0.91]$} & 0.91 & {$[0.89,0.93]$} \\
\hline$\rho^{g}$ & 0.8 & {$[0.61,0.94]$} & 0.88 & {$[0.82,0.96]$} & 0.87 & {$[0.83,0.92]$} & 0.87 & {$[0.85,0.96]$} & 0.90 & {$[0.81,0.96]$} \\
\hline$\rho^{z}$ & 0.8 & {$[0.61,0.94]$} & 0.74 & {$[0.62,0.86]$} & 0.77 & {$[0.65,0.87]$} & 0.85 & {$[0.76,0.92]$} & 0.81 & {$[0.66,0.92]$} \\
\hline$\rho^{\tau}$ & 0.8 & {$[0.61,0.94]$} & 0.81 & {$[0.75,0.85]$} & 0.80 & {$[0.73,0.84]$} & 0.83 & {$[0.81,0.88]$} & 0.77 & {$[0.70,0.82]$} \\
\hline$\sigma_{a, p}$ & 0.005 & {$[0.001,0.01]$} & 0.010 & {$[0.009,0.013]$} & 0.012 & {$[0.011,0.015]$} & 0.01 & {$[0.009,0.012]$} & 0.012 & {$[0.01,0.014]$} \\
\hline$\sigma_{g, p}$ & 0.005 & {$[0.001,0.01]$} & 0.021 & {$[0.017,0.027]$} & 0.023 & {$[0.020,0.026]$} & 0.02 & {$[0.019,0.025]$} & 0.023 & {$[0.019,0.028$} \\
\hline$\sigma_{z, p}$ & 0.2 & {$[0.07,0.39]$} & 0.29 & {$[0.24,0.36]$} & 0.28 & {$[0.22,0.36]$} & 0.30 & {$[0.23,0.36]$} & 0.26 & {$[0.20,0.35]$} \\
\hline$\sigma_{\tau, p}$ & 0.005 & {$[0.001,0.01]$} & 0.010 & {$[0.008,0.013]$} & 0.010 & {$[0.009,0.012]$} & 0.01 & {$[0.008,0.013]$} & 0.01 & {$[0.008,0.013$} \\
\hline
\end{tabular}

Table 4: Smoothed estimates of measurement error.

\begin{tabular}{|c|c|c|c|c|c|c|}
\hline \multicolumn{7}{|l|}{ Italy } \\
\hline & & $b_{t}$ & $g_{t}$ & $T_{t}$ & $y_{t}$ & $R_{t}$ \\
\hline \multirow{2}{*}{ Nonlinear $\delta^{A}=0.0947$} & " mean absolute value & 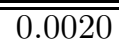 & 0.0015 & 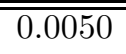 & $\overline{00.0058}$ & 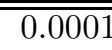 \\
\hline & relative standard deviation & 0.128 & 0.093 & 0.195 & 0.296 & 0.108 \\
\hline \multirow{2}{*}{ Nonlinear $\delta^{A}=0.3788$} & mean absolute value & 0.0021 & 0.0012 & 0.0040 & 0.0059 & 0.0001 \\
\hline & relative standard deviation & 0.128 & 0.093 & 0.195 & 0.296 & 0.108 \\
\hline \multirow{2}{*}{ Linear } & mean absolute value & 0.0021 & 0.0012 & 0.0052 & 0.0051 & 0.0001 \\
\hline & relative standard deviation & 0.089 & 0.059 & 0.295 & 0.375 & 0.013 \\
\hline \multirow[t]{2}{*}{ Greece } & & & & & & \\
\hline & & $b_{t}$ & $g_{t}$ & $T_{t}$ & $y_{t}$ & $R_{t}$ \\
\hline \multirow{2}{*}{ Nonlinear $\delta^{A}=0.0947$} & " mean absolute value & 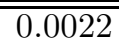 & 0.0057 & 0.0032 & 0.0071 & $\overline{0.0003}$ \\
\hline & relative standard deviation & 0.089 & 0.137 & 0.105 & 0.227 & 0.114 \\
\hline \multirow{2}{*}{ Nonlinear $\delta^{A}=0.3788$} & mean absolute value & 0.0027 & 0.0048 & 0.0035 & 0.0069 & 0.0003 \\
\hline & relative standard deviation & 0.116 & 0.115 & 0.113 & 0.219 & 0.135 \\
\hline \multirow{2}{*}{ Linear } & mean absolute value & 0.0023 & 0.0044 & 0.0034 & 0.0060 & 0.0003 \\
\hline & relative standard deviation & 0.162 & 0.310 & 0.208 & 0.436 & 0.020 \\
\hline
\end{tabular}


Table 5: Model-implied $\tilde{b}^{\max }$ and estimated $\tilde{b}^{*}$

\begin{tabular}{lcccccccc}
\hline & Italy $\delta^{A}=0.3788$ & \multicolumn{2}{c}{ Italy $\delta^{A}=0.0947$} & \multicolumn{2}{c}{ Greece $\delta^{A}=0.3788$} & \multicolumn{2}{c}{ Greece $\delta^{A}=0.0947$} \\
& median & {$[5,95]$} & median & {$[5,95]$} & median & {$[5,95]$} & median & {$[5,95]$} \\
\hline \hline$\tilde{b}^{\text {max }}$ & 2.45 & {$[2.38,2.49]$} & 2.47 & {$[2.24,2.51]$} & 3.32 & {$[3.15,3.36]$} & 3.26 & {$[3.07,3.35]$} \\
$\tilde{b}^{*}$ & 1.52 & {$[1.46,1.6]$} & 1.6 & {$[1.44,1.78]$} & 1.67 & {$[1.58,1.78]$} & 1.45 & {$[1.40,1.57]$} \\
$\beta^{\text {pol }}$ & 0.62 & {$[0.59,0.67]$} & 0.65 & {$[0.58,0.73]$} & 0.5 & {$[0.48,0.54]$} & 0.45 & {$[0.42,0.48]$} \\
\hline
\end{tabular}

